\title{
The Cognitive Benefits of Learning Native Language and Bilingualism in a Minority Group
}

\author{
Genc Struga ${ }^{1 *}$, Thomas Bak ${ }^{2}$, EnverRoshi ${ }^{3}$ and Stavros Baloyannis ${ }^{4}$ \\ ${ }^{1}$ Department of Neuroscience, University Hospital Mother Teresa, Albania \\ ${ }^{2}$ University of Edinburgh, $U K$ \\ ${ }^{3}$ Chief of Department of Public Health, Faculty of Medicine, Albania \\ ${ }^{4}$ Director Institute for Research on Alzheimer's disease, Professor Emeritus Aristotelian University of Thessaloniki, Greece
}

Submission: December 15, 2017; Published: May 24, 2018

*Corresponding author: Genc Struga, Department of Neuroscience, University Hospital Mother Teresa, Albania, Email: genc.struga@gmail.com

\begin{abstract}
Objective: Studying the Arvanites a bilingual population in Greece that speak Arvanitika a dialect of Albanian language still spoken in vast areas of Greece is classified as minority language and in risk of extinction as endangered. The study aim to show the possible benefit in cognitive and cognitive related dysfunction of native speakers of Arvanitika from bilingualism [1].

Method: This is a population cohort study including bilingual speakers without exclusion criteria, sampling in the areas where Arvanite population traditionally lived achieving a sample number statistically important of 400 responders between 2018-2022 in a population unofficially ranging from $200000-16000000$ or $15 \%$ of population and the comparable the same number of monolingual Greek speaker with similar background.
\end{abstract}

Conclusion: A statistically analysis of data indicating benefit of bilingualism and importance of acquiring "mother linguae" in minority population group and how this influence further cognitive functions, capability for further learning including lower incidence of cognitive disorders.

Keywords: Cognition; Dementia; Speech brain processing; Albanian language; Arvanitika; Minorities; Greek language

\section{Background}

Studying the Arvanites a bilingual population in Greece that speak Arvanitika a dialect of Albanian language [1] still spoken in vast areas of Greece [2] is classified as minority language and in risk of extinction as endangered [3]. The study aim to show the possible benefit in cognitive and cognitive related dysfunction of native speakers of Arvanitika from bilingualism [2] also the ability for further learning and acquisition of other languages.

It is well known the effect of bilingualism on cognitive function by several studies which have demonstrated a better performance of bilingual while Neuroimaging studies concluded a greater volume of frontal lobe and better structural integrity [4]. This might be the consequence of long term necessity to switch between the languages. The benefit of speaking the "mother linguae" it is been demonstrated that is cohort related, the subject that appear old in bilingualism have more cognitive benefits. Previous studies have demonstrated that bilingual speakers have a postponement in cognitive impairment and dementia for e period to maximum of 5 years compare with speakers of one language [5].

\section{Method}

This is a population study including bilingual speakers without exclusion criteria, sampling in the areas where Arvanite population traditionally lived achieving a sample number statistically important of 400 responders between 2018-2022 in a population unofficially ranging from 200000-16000000 or $15 \%$ of population [2].

The samples are taken from areas where traditionally have with main presence of Arvanites which are more than 500 villages in different province of Greece dominantly in Epirus, Follorina, CastoriaEubea, Attica, Corinth Boetia, Argolis, Messenia, Acheae, Peloponnese ,Thraka . Other settlements are in Andros, Hydra, Poros, Spetsai, Salamis [2]. To be eligible, potential participants have to be 65 years or older with no previous diagnosis of dementia, they should identify as Arvanites or Greek, bilingual in Arvanitika and Greek or otherwise.

The purpose of the study would be in comparing cognitive performance in Greek speaking only and Arvanitika -Greek 


\section{Open Access Journal of Neurology \& Neurosurgery}

bilinguals aiming the comparable the same number of monolingual Greek speaker with similar background. There is been a critical view of studies performed and the influence of many factors including the right methodology of studying a population group, cognitive tests used for screening, statistical analysis, environment factors, education, social economic status, cultural and political factors therefore study aim to address to this issue.

The emerge in questionnaire of all factors such as health status, life style, social economic level, education background, cultural and political factors including up to date promising test in cognition used in bilingualism studies Addenbrooke's Cognitive Examination-III ( ACE -III) and The Test of Everyday Attention (TEA) [6-8]. The ACE-R sensitivity to mild dementia (84-94\% depending on cut-off point) is better than the MMSE. The original ACE included the mini-mental state examination (MMSE) or Folstein test, along with fronto-executive and extra visuospatial items. However, weaknesses were identified in the ACE, which prompted the development of the Adden brooke's Cognitive Examination-Revised (ACE-R) to facilitate crosscultural usage and improve sensitivity. In light of weaknesses of certain domains in ACE-R, such as repetition, comprehension, visuospatial, items on the ACE-R were replaced to form the ACEIII [8].

The TEA is the only test of attention that gives a broad overview by breaking attention down into theoretically distinct factors, which can then be used as the basis of a detailed analysis of an individual's cognitive resources. These test is being used recently to many bilingual studies, interesting part of it is namely diagnosing dementia in non-dominant language in linguistic minorities [6,7]. Considering practical difficulties of individual survey, the advertising and online option was taken in consideration

\section{Conclusion}

A statistically analysis of data indicating benefit of bilingualism and importance of acquiring "mother linguae" in minority population group and how this influence further cognitive functions, capability for further learning including lower incidence of cognitive disorders $[6,9,10]$.

\section{References}

1. Tsitsipis LD (2003) A linguistic anthropology of praxis and language shift: Arvanitika (Albanian) and Greek in Contact. Oxford: Clarendon Press, USA.

2. Skutsch C, Martin R (2005) Encyclopedia of the world's minorities. Routledge, New York, USA.

3. Jones MP (2013) Endangered languages and linguistic diversity in the European union author.

4. Padilla C, Mendez MF, Jimenez EE, Teng E (2016) Bilingualism in older Mexican-American immigrants is associated with higher scores on cognitive screening. BMC Geriatrics 16: 189.

5. Chertkow H, Whitehead V, Phillips N, Wolfson C, Atherton J, et al. (2010) Multilingualism (but not always bilingualism) delays the onset of Alzheimer disease: evidence from a bilingual community. Alzheimer Dis Assoc Disord 24(2): 118-125.

6. Bak TH, Nissan J, Allerhand M, Deary IJ (2014) Does bilingualism influence cognitive ageing? Ann Neurol 75(6): 959-963.

7. Robertson IH, Ward T, Ridgeway V, Smith IN (1994) The Test of everyday attention (TEA). Reviewed by Dr. Andrew W McAnespie chartered clinical psychologist-hull and east riding community health NHS Trust Honorary Clinical Lecturer -The University of Hull, Thames Valley Test Company, UK.

8. Noone P (2015) Addenbrooke's cognitive examination-III. Occupational Medicine 65(5): 418-420.

9. Struga G (2016) Why native Albanian speaker have an easier approach toward acquisition of other languages? J Neurol Stroke 4(5): 00153.

10. Atkinson AL (2016) Does bilingualism delay the development of dementia? Journal of European Psychology Students, 7(1): 43-50.

\section{Your next submission with Juniper Publishers} will reach you the below assets

- Quality Editorial service

- Swift Peer Review

- Reprints availability

- E-prints Service

- Manuscript Podcast for convenient understanding

- Global attainment for your research

- Manuscript accessibility in different formats

( Pdf, E-pub, Full Text, Audio)

- Unceasing customer service

Track the below URL for one-step submission https://juniperpublishers.com/online-submission.php 